\title{
COOPERATION IN A CONFLICT OF $N$ PERSONS UNDER UNCERTAINTY
}

\author{
V.I. Zhukovskiy ${ }^{1}$ K.N. Kudryavtsev ${ }^{2,3}$, S.A. Shunailova ${ }^{2}$, I.S. Stabulit ${ }^{2}$ \\ ${ }^{1}$ Lomonosov Moscow State University, Moscow, Russian Federation \\ 2 South Ural State University, Chelyabinsk, Russian Federation \\ ${ }^{3}$ Chelyabinsk State University, Chelyabinsk, Russian Federation \\ E-mails: zhkvlad@yandex.ru, kudrkn@gmail.com, shunailovasa@susu.ru, \\ irisku76@mail.ru
}

\begin{abstract}
The paper considers a model of a conflict system with $N$ active participants with their own interests when exposed to an uncertain factor. At the same time, decision-makers do not have any statistical information about the possible implementation of an uncertain factor i.e. they only know the many possible realizations of this factor - uncertainties. Under the assumption that the participants of to the conflict can coordinate their actions in the decision-making process the model is formalized as a cooperative $N$-person game without side payments and under uncertainty. In this paper, we introduce a new principle of coalitional equilibration (CE). The integration of individual and collective rationality (from theory of cooperative games without side payments) and this principle allows us to formalize the corresponding concept of $\mathrm{CE}$ for a conflict of $N$ persons under uncertainty. At the same time, uncertainty is taken into account along with using the concept of the "analogue of maximin" proposed earlier in the our works and the "strong guarantees" constracted on its basis. Next, we establish sufficient conditions for existence of coalitional equilibrium, which are reduced to saddle point design for the Germeier convolution of guaranteed payoffs. Following the above-mentioned approach of E. Borel, J. von Neumann and J. Nash, we also prove existence of coalitional equilibrium in the class of mixed strategies under standard assumptions of mathematical game theory (compact uncertainties, compact strategy sets, and continuous payoff functions). At the end of the paper, some directions or further research are given.

Keywords: cooperative game; uncertainty; Germeier convolution; game of guarantees.
\end{abstract}

\section{Introduction}

In mathematical modelling of complex socio-economic systems, the problem on predicting the actions of several decision-makers takes place rather often. As a rule, interests of the decision-makers do not coincide. At the same time, the incompleteness and inaccuracy of information about the system should be taken into account in the mathematical model. Such models are studied in the game theory under uncertainty. The mathematical model of cooperation studied in this article is described by a cooperative $N$-player normal form game under uncertainty without side payments. We assume that conflicting parties know merely the variation ranges (intervals) of uncertain factors, without any probabilistic characteristics. A proper consideration of uncertainties in the models of real conflicts gives more adequate results, which is confirmed by a huge number of publications (the Google Scholar database contains over 1 million research works with 
keywords "mathematical modelling under uncertainty"). Uncertainty often occurs due to incomplete (inaccurate) knowledge about the strategies implemented by conflicting parties: C. Shannon was used to say, "Information is the resolution of uncertainty." As mentioned earlier, an economic system often suffers from sudden exogenous disturbances (e.g., the varying number and range of supplies, product price fluctuations caused by demandsupply dynamics) and also endogenous disturbances (e.g., the breakdowns and failures of industrial equipment, mistakes in planning and product design); the appearance of new technologies may affect ecological systems; disturbing factors in mechanical systems are weather conditions (temperature, pressure, humidity, etc.). Therefore we naturally face the following question: what are possible ways to take into account the cooperative character of a conflict and existing uncertainties during strategy choice?

A distinctive feature of each cooperative conflict is a proper consideration of the interests of any admissible coalition, i.e. a group of players (conflicting parties) with a coordinated choice of their strategies for achieving as best outcomes as possible. Our framework will proceed from several assumptions as follows.

First, if the members of a coalition agree about joint actions by negotiations, then their agreement remains in force during the whole game, i.e., any agreements are compulsory.

Second, the players do not distribute any part of their payoffs to other players (i.e., we will be confined to the games without side payoffs, also called the games with nontransferable payoffs).

Third, the payoff of an empty coalition is zero (personality); in accordance with this principle, only active players may obtain nonzero payoffs.

\section{Game of Guarantees}

Consider a mathematical model of a conflict described by a cooperative $N$-player normal form game under uncertainty with non-transferable payoffs

$$
\Gamma=\left\langle\mathbb{N}=\{1, \ldots, N\},\left\{X_{i}\right\}_{i \in \mathbb{N}}, Y^{X},\left\{f_{i}(x, y)\right\}_{i \in \mathbb{N}}\right\rangle .
$$

In this game, $\mathbb{N}=\{1, \ldots, N\}$ denotes the set of serial numbers (indexes) of players; each of $N$ conflicting parties chooses his/her/its strategy $x_{i} \in X_{i} \subset \mathbb{R}^{n_{i}}(i \in \mathbb{N})$, whereby forming a strategy profile $x=\left(x_{1}, \ldots, x_{N}\right) \in X=\prod_{i \in \mathbb{N}} X_{i} \subset \mathbb{R}^{n}\left(n=\sum_{i \in \mathbb{N}} n_{i}\right)$; regardless of their actions, (an interval) uncertainty $y \in Y \subset \mathbb{R}^{m}$ is realized in $\Gamma$; a payoff function $f_{i}(x, y)$ of each $i$-th player is defined on all pairs $(x, y) \in X \times Y$, and its value in a specific strategy profile gives the payoff of the $i$-th player. At conceptual level, each $i$-th player in the game $\Gamma$ seeks for choosing a strategy $x_{i}^{*}(i \in \mathbb{N})$ that would maximize his/her/its payoff under any admissible coalition and any realization of an uncertain factor $y(x): X \rightarrow Y$, $y(\cdot) \in Y^{X}$ (in particular, strategic uncertainty).

A well-known English proverb states that "Never cackle till your egg is laid". This emphasizes a crucial role of uncertainty, but taking uncertain factors into consideration makes the payoff functions $f_{i}(x, Y)=\bigcup_{y \in Y} f_{i}(x, y)$ multi-valued. Such a property inevitably complicates further analysis of the cooperative games $\Gamma$. Therefore our idea is to assess the performance of each $i$-th player in $\Gamma$ using a lower guarantee $f_{i}[x]$ of the payoff function $f_{i}(x, y)$. We suggest the following definition for such guarantees [1].

\footnotetext{
${ }^{1}$ Claude Elwood Shannon, (1916-2001), was an American mathematician and electrical engineer who laid the theoretical foundations for digital circuits and information theory.
} 
For any $y \in Y$

$$
f_{i}[x]=\min _{y \in Y} f_{i}(x, y)
$$

Really, this formula implies $f_{i}[x] \leqslant f_{i}(x, y) \forall y \in Y$, and hence the performance of the $i$-th player in the game $\Gamma$ can be assigned the lower bound $f_{i}[x]$ under any the strategy profile $x \in X$. In other words, for any uncertainty $y \in Y$ the payoff function $f_{i}(x, y)$ cannot be smaller than $f_{i}[x]$. Note that existence of a continuous scalar function $f_{i}[x]$ over $X$ follows from the compactness (closedness and boundedness) of the sets $X_{i}(i \in \mathbb{N})$ and $Y$ and also from the continuity of $f_{i}(x, y)$ over $X \times Y$.

\section{Coalitional Equilibrium}

Denote by $2^{\mathbb{N}}$ the set of all coalitions (nonempty subsets of the set $\mathbb{N}$ ), i.e., $2^{\mathbb{N}}=$ $\left\{K \mid K \subseteq 2^{\mathbb{N}}\right\}$. For each coalition $K \in 2^{\mathbb{N}}$, let $-K$ be the set $\mathbb{N} \backslash K$, that is, $-K=\mathbb{N} \backslash K$; in particular, $-i=\mathbb{N} \backslash\{i\}$. Then the coalitional structure $\{K,-K\}$ is a partition of the whole player set $\mathbb{N}$. For this coalitional structure, any strategy profile $x=\left(x_{1}, \ldots, x_{N}\right)$ can be represented as $x=\left(x_{K}, x_{-K}\right)$, where $x_{K} \in X_{K}=\prod_{j \in K} X_{j}$ and $x_{-K} \in X_{-K}=\prod_{j \in \mathbb{N} \backslash K} X_{j}$.

Recall a pair of important properties from theory of cooperative games without side payments [2]. For a strategy profile $x^{*} \in X$ in the game of guarantees

$$
\Gamma^{g}=\left\langle\mathbb{N},\left\{X_{i}\right\}_{i \in \mathbb{N}},\left\{f_{i}[x]\right\}_{i \in \mathbb{N}}=\min _{y \in Y} f_{i}(x, y)\right\rangle,
$$

we say that

(a) the individual rationality condition (IRC) holds if

$$
f_{i}\left[x^{*}\right] \geq f_{i}^{0}=\max _{x_{i} \in X_{i}} \min _{x_{-i} \in X_{-i}} f_{i}\left[x_{i}, x_{-i}\right]=\min _{x_{-i} \in X_{-i}} f_{i}\left[x_{i}^{0}, x_{-i}\right](i \in \mathbb{N}),
$$

where $x=\left(x_{i}, x_{-i}\right)$ and $X_{-i}=\prod_{j \in \mathbb{N} \backslash\{i\}} X_{j}$; so using the maximin strategy $x_{i}^{0}$, the $i$-th player obtains a payoff $f_{i}\left[x_{i}^{0}, x_{-i}\right] \geqslant f_{i}^{0} \forall x_{-i} \in X_{-i}(i \in \mathbb{N})$;

(b) the collective rationality condition (ColRC) holds if the strategy $x^{*}$ is a Pareto maximal alternative in the $N$-criteria choice problem $\Gamma_{v}^{g}=\left\langle X,\left\{f_{i}[x]\right\}_{i \in \mathbb{N}}\right\rangle$; in other words, for all $x \in X$ the system of inequalities $f_{i}[x] \geqslant f_{i}\left[x^{*}\right](i \in \mathbb{N})$ is inconsistent, where at least one inequality is strict. (If for any $x \in X$ we have $\sum_{i \in \mathbb{N}} f_{i}[x] \leqslant \sum_{i \in \mathbb{N}} f_{i}\left[x^{*}\right]$, then $x^{*}$ is a Pareto maximal alternative in the problem $\left.\Gamma_{v}^{g}\right)$.

By modifying the concepts of Nash and Berge equilibria [3-6], we introduce

(c) the coalitional rationality condition (CoalRC) for the game of guarantees $\Gamma^{g}$ in the following way:

$$
f_{i}\left[x^{*}\right] \geqslant f_{i}\left[x_{K}, x_{-K}^{*}\right] \quad \forall x_{K} \in X_{K}, \forall K \in 2^{\mathbb{N}}(i \in \mathbb{N}) .
$$

Definition 1. A strategy profile $x^{*} \in X$ is called a coalitional equilibrium (CE) if $x^{*}$ simultaneously satisfies IRC, ColRC, and CoalRC in the game of guarantees $\Gamma^{g}$.

Remark 1. According to IRC, a player benefits from building coalitions with other players if the resulting payoff is not smaller than his/her/its payoff yielded by the maximin 
strategy. ColRC gives the largest payoff vector to a player (in the vector sense!). Finally, CoalRC makes his/her/its payoff stable against the deviations of separate players or any admissible coalitions from $x^{*}$.

The coalitional equilibrium in 3-person games was introduced in $[7,8]$.

\section{Sufficient Condition}

According to Definition 1, a CE $x^{*}$ must satisfy IRC, ColRC, and CoalRC. However, all these conditions follow from $\left(N^{2}+1\right)$ inequalities of the form

$$
\begin{aligned}
& f_{i}\left[x^{*}\right] \geqslant f_{i}\left[x_{j}^{*}, x_{-j}\right] \quad \forall x_{-j} \in X_{-j} \quad(i, j \in \mathbb{N}), \\
& \sum_{i \in \mathbb{N}} f_{i}[x] \leqslant \sum_{i \in \mathbb{N}} f_{i}\left[x^{*}\right] \quad \forall x \in X,
\end{aligned}
$$

where $x^{*}=\left(x_{1}^{*}, \ldots, x_{N}^{*}\right)$.

To formulate sufficient conditions for existence of CE, we will employ the original approach [9]. For this purpose, introduce an $N$-dimensional vector $z=\left(z_{1}, \ldots, z_{N}\right) \in X$ and the function $\varphi(x, z)$ as the Germeier convolution [10] of functions $\varphi_{r}(x, z)(r=$ $1, \ldots, N+1)$ :

$$
\begin{gathered}
\varphi_{j}(x, z)=\max _{i \in \mathbb{N}}\left\{f_{i}\left[z_{j}, x_{-j}\right]-f_{i}[z]\right\} \quad(j \in \mathbb{N}), \\
\varphi_{N+1}(x, z)=\sum_{i \in \mathbb{N}} f_{i}[x]-\sum_{i \in \mathbb{N}} f_{i}[z], \\
\varphi(x, z)=\max _{r=1, \ldots, N+1} \varphi_{r}(x, z) .
\end{gathered}
$$

A saddle point $\left(x^{0}, z^{*}\right) \in X \times Y$ of the scalar function $\varphi(x, z)(2)$ is given by the chain of inequalities

$$
\varphi\left(x, z^{*}\right) \leqslant \varphi\left(x^{0}, z^{*}\right) \leqslant \varphi\left(x^{0}, z\right) \quad \forall x, z \in X .
$$

Theorem 1. If $\left(x^{0}, z^{*}\right) \in X \times X$ is a saddle point of the function $\varphi(x, y)$, then the minimax strategy $z^{*}$ is the coalitional equilibrium in the game $\Gamma^{g}$.

Proof. Really, formula (2) with $z=x^{0}$ gives $\varphi\left(x^{0}, x^{0}\right)=0$. Then, using transitivity and (3),

$$
\left[\varphi\left(x^{0}, z^{*}\right) \leq 0\right] \Rightarrow\left[\varphi\left(x, z^{*}\right) \leq 0 \quad \forall x \in X\right]
$$

and the conclusion follows by (2).

Remark 2. According to Theorem 1, CE design is reduced to calculation of a saddle point $\left(x^{0}, z^{*}\right)$ for the Germeier convolution $\varphi(x, z)(3)$. Therefore, we have developed a constructive method of $\mathrm{CE}$ design in the game $\Gamma$, which includes the following steps:

first, define the scalar function $\varphi(x, z)$ using formulas (2) and (3);

second, find a saddle point $\left(x^{0}, z^{*}\right)$ of the function $\varphi(x, z)$ (see the chain of inequalities (4));

third, calculate the values $f_{i}\left[x^{*}\right](i \in \mathbb{N})$.

Then the pair $\left(z^{*}, f\left[z^{*}\right]=\left(f_{1}\left[z^{*}\right], \ldots, f_{N}\left[z^{*}\right]\right)\right) \in X \times \mathbb{R}^{N}$ is a coalitional equilibrium in the game $\Gamma^{g}$ : the players should apply their strategies from the profile $z^{*}$, thereby obtaining the guaranteed payoffs $f_{i}\left[z^{*}\right]$. 


\section{Existence of Coalitional Equilibrium in Mixed Strategies}

One must be very optimistic to look for a coalitional equilibrium in the class of pure strategies, even for the two-player games. Adhering to the approach of E. Borel [11], J. von Neumann [12], J. Nash [3, 4] and their followers, we will establish existence of mixed strategy CE. Let us begin with a series of auxiliary results laying the foundations of a corresponding existence theorem.

\subsection{Auxiliary Results}

Denote by comp $\mathbb{R}^{n_{i}}$ the set of all compact (closed and bounded) subsets of the Euclidean $n_{i}$-dimensional space $\mathbb{R}^{n_{i}}$, and write $f_{i}(\cdot) \in C(\mathrm{X} \times \mathrm{Y})$ if a scalar function $f_{i}(x, y)$ is continuous over $\mathrm{X} \times \mathrm{Y}$.

Get back to the cooperative game without side payments $\Gamma$. Without special mention, assume that the elements of the ordered quadruple $\Gamma$ satisfy the following requirements.

Condition 1.

$$
\mathrm{X}_{i} \in \operatorname{comp} \mathbb{R}^{n_{i}}(i \in \mathbb{N}), \quad \mathrm{Y} \in \operatorname{comp} \mathbb{R}^{m}, \quad f_{i}(\cdot) \in C(\mathrm{X} \times \mathrm{Y})
$$

Pass to the mixed extension of the game $\Gamma^{g}$, which includes mixed strategies, mixed strategy profiles, and expected payoffs.

Suppose that the game $\Gamma$ satisfies inequalities $(5)$; then $f_{i}(x, y)$ is continuous over the product $\mathrm{X} \times \mathrm{Y}$ of compact sets, where $\mathrm{X}=\prod_{i \in \mathbb{N}} \mathrm{X}_{i}$. For each compact set $\mathrm{X}_{i} \subset \mathbb{R}^{n_{i}}$ $(i \in \mathbb{N})$, construct the Borel $\sigma$-algebra $\mathfrak{B}\left(\mathrm{X}_{i}\right)$, i.e., the set of all subsets of $\mathrm{X}_{i}$ such that $\mathrm{X}_{i} \in \mathfrak{B}\left(\mathrm{X}_{i}\right)$, and $\mathfrak{B}\left(\mathrm{X}_{i}\right)$ is closed with respect to the complement and union of a countable number of sets from $\mathfrak{B}\left(\mathrm{X}_{i}\right)$; in addition, $\mathfrak{B}\left(\mathrm{X}_{i}\right)$ is the minimal $\sigma$-algebra that contains all closed subsets of a compact set $\mathrm{X}_{i}$. Within the framework of mathematical game theory, a mixed strategy $\nu_{i}(\cdot)$ of $i$-th player is identified with a probability measure over a compact set $\mathrm{X}_{i}$. A probability measure is a nonnegative scalar function $\nu_{i}(\cdot)$ defined on the Borel $\sigma$-algebra $\mathfrak{B}\left(\mathrm{X}_{i}\right)$ of all subsets of a compact set $\mathrm{X}_{i} \subset \mathbb{R}^{n_{i}}$ that satisfies the following two conditions:

(1) $\nu_{i}\left(\bigcup_{k} Q_{k}^{(i)}\right)=\bigcup_{k} \nu_{i}\left(Q_{k}^{(i)}\right)$ for any sequence $\left\{Q_{k}^{(i)}\right\}_{k=1}^{\infty}$ of pairwise disjoint elements from $\mathfrak{B}\left(\mathrm{X}_{i}\right)$ (countable additivity);

(2) $\nu_{i}\left(\mathrm{X}_{i}\right)=1$ (normalization), which implies $\nu_{i}\left(Q^{(i)}\right) \leq 1$ for all $Q^{(i)} \in \mathfrak{B}\left(\mathrm{X}_{i}\right)$.

Denote by $\left\{\nu_{i}\right\}$ the set of all mixed strategies of the $i$-th player $(i \in \mathbb{N})$. Construct a mixed strategy profile as the product measure

$$
\nu(d x)=\nu_{1}\left(d x_{1}\right) \ldots \nu_{N}\left(d x_{N}\right),
$$

and let $\{\nu\}$ be the set of all such profiles. In addition, denote by $f_{i}[\nu]=\int_{X} f_{i}[x] \nu(d x)$ the expected payoff of the $i$-th player. Then the mixed extension of the game of guarantees $\Gamma^{g}$ has the form

$$
\widetilde{\Gamma}^{g}=\left\langle\mathbb{N}=\{1, \ldots, N\},\left\{\nu_{i}\right\}_{i \in \mathbb{N}},\left\{f_{i}[\nu]=\int_{X} f_{i}[x] \nu(d x)\right\}_{i \in \mathbb{N}}\right\rangle .
$$

Similarly to Definition 1, introduce 
Definition 2. A mixed strategy profile $\nu^{*}(\cdot) \in\{\nu\}$ is called a coalitional equilibrium $(C E)$ in the mixed extension (6) (equivalently, a coalitional equilibrium (CE) in mixed strategies in the game $\widetilde{\Gamma}^{g}$ ) if

first, the profile $\nu^{*}(\cdot)$ is coalitionally rational in game (6), i.e.,

$$
f_{i}\left[\nu_{1}, \ldots, \nu_{j}^{*}, \ldots, \nu_{N}\right] \leqslant f_{i}\left[\nu^{*}\right] \quad \forall \nu_{k}(\cdot) \in\left\{\nu_{k}\right\} \quad(k \in \mathbb{N} \backslash\{j\} ; i, j \in \mathbb{N})
$$

(denote by $\left\{\nu^{*}\right\}$ the set of all coalitional equilibria in game (6));

second, $\nu^{*}(\cdot)$ is a Pareto maximal alternative in the $N$-criteria choice problem

$$
\widetilde{\Gamma}_{v}^{g}=\left\langle\left\{\nu^{*}\right\},\left\{f_{i}[\nu]\right\}_{i \in \mathbb{N}}\right\rangle
$$

i.e., for all $\nu(\cdot) \in\left\{\nu^{*}\right\}$ the system of inequalities

$$
f_{i}[\nu] \geqslant f_{i}\left[\nu^{*}\right] \quad(i \in \mathbb{N})
$$

with at least strict inequality, is inconsistent.

It is possible to suggest an obvious sufficient condition of Pareto maximality, see Remark 3.

Remark 3. A mixed strategy profile $\nu^{*}(\cdot) \in\left\{\nu^{*}\right\}$ is a Pareto maximal alternative in $\widetilde{\Gamma}_{v}^{g}=\left\langle\left\{\nu^{*}\right\},\left\{f_{i}[\nu]\right\}_{i \in \mathbb{N}}\right\rangle$ if

$$
\max _{\nu(\cdot) \in\left\{\nu^{*}\right\}} \sum_{i \in \mathbb{N}} f_{i}[\nu]=\sum_{i \in \mathbb{N}} f_{i}\left[\nu^{*}\right] .
$$

Proposition 1. In the game $\Gamma^{g}$ with sets $\mathrm{X}_{i} \in \operatorname{comp} \mathbb{R}^{n_{i}}$ and $f_{i}[\cdot] \in C(X)(i \in \mathbb{N})$, the function

$$
\varphi(x, z)=\max _{r=1, \ldots, N+1} \varphi_{r}(x, z)
$$

satisfies the inequality

$$
\max _{r=1, \ldots, N+1} \int_{\mathrm{X} \times \mathrm{X}} \varphi_{r}(x, z) \mu(d x) \nu(d z) \leqslant \int_{\mathrm{X} \times \mathrm{X}} \max _{r=1, \ldots, N+1} \varphi_{r}(x, z) \mu(d x) \nu(d z)
$$

for any $\mu(\cdot) \in\{\nu\}$ and $\nu(\cdot) \in\{\nu\}$; recall that the scalar functions $\varphi_{r}(x, z)$ are defined by (2).

Inequality (9) was proved in [9].

Remark 4. In fact, formula (9) generalizes the well-known property of maximization: the maximum of a sum does not exceed the sum of the maximums.

Proposition 2. If conditions (5) hold in the game $\Gamma^{g}$, then the function $\varphi(x, z)$ (8) is continuous over $\mathrm{X} \times(\mathrm{Z}=\mathrm{X})$.

The proof of a more general result (the maximum of a finite number of continuous functions is continuous) can be found in many textbooks on operations research, e.g., in $[13-15]$. 


\subsection{Existence Theorem}

The central result of this section, i.e. the existence of a coalitional equilibrium in mixed strategies, is established in the game $\Gamma^{g}$ under conditions (5).

Theorem 2. If the sets $\mathrm{X}_{i} \in \operatorname{comp} \mathbb{R}^{n_{i}}$ and $f_{i}[\cdot] \in C(\mathrm{X})(i \in \mathbb{N})$ in the game $\Gamma^{g}$, then there exists a coalitional equilibrium in mixed strategies in this game.

Proof. Consider an auxiliary zero-sum two-player game

$$
\Gamma^{a}=\langle\{1,2\},\{\mathrm{X}, \mathrm{Z}=\mathrm{X}\}, \varphi(x, z)\rangle .
$$

In the game $\Gamma^{a}$, the set $\mathrm{X}$ of strategies $x$ chosen by the 1-st player (which seeks to maximize $\varphi(x, z))$ coincides with the set of strategy profiles of the game $\Gamma^{g}$. A solution of the game $\Gamma^{a}$ is a saddle point $\left(x^{0}, z^{*}\right) \in \mathrm{X} \times \mathrm{X}$; for all $x \in X$ and each $z \in \mathrm{X}$, it satisfies the chain of inequalities

$$
\varphi\left(x, z^{*}\right) \leqslant \varphi\left(x^{0}, z^{*}\right) \leqslant \varphi\left(x^{0}, z\right) .
$$

Now, associate the game $\Gamma^{a}$ with its mixed extension

$$
\widetilde{\Gamma}^{a}=\langle\{1,2\},\{\mu\},\{\nu\}, \varphi(\mu, \nu)\rangle,
$$

where $\{\nu\}$ and $\{\mu\}=\{\nu\}$ denote the sets of mixed strategies $\nu(\cdot)$ and $\mu(\cdot)$ of the 1-st and 2 -nd players, respectively. The payoff function of the 1-st player is the expectation

$$
\varphi(\mu, \nu)=\int_{\mathrm{X} \times \mathrm{X}} \varphi(x, z) \mu(d x) \nu(d z) .
$$

The solution of the game $\widetilde{\Gamma}^{a}$ (the mixed extension of the game $\Gamma^{a}$ ) is also a saddle point $\left(\mu^{0}, \nu^{*}\right)$ defined by the two sequential inequalities

$$
\varphi\left(\mu, \nu^{*}\right) \leqslant \varphi\left(\mu^{0}, \nu^{*}\right) \leqslant \varphi\left(\mu^{0}, \nu\right)
$$

for any $\nu(\cdot) \in\{\nu\}$ and $\mu(\cdot) \in\{\nu\}$.

Sometimes, this pair $\left(\mu^{0}, \nu^{*}\right)$ is called a solution of the game $\Gamma^{a}$ in mixed strategies.

In 1952, I. Gliksberg [16] established the existence theorem of a mixed strategy Nash equilibrium for a noncooperative game of $N \geqslant 2$ players. Applying this theorem to the zero-sum two-player game $\Gamma^{a}$ as a special case, we obtain the following result. In the game $\Gamma^{a}$, let the set $\mathrm{X} \subset \mathbb{R}^{n}$ be nonempty and compact and also let the payoff function $\varphi(x, z)$ of the 1-st player be continuous over $\mathrm{X} \times \mathrm{X}$ (note that the continuity of $\varphi(x, z)$ is assumed in Proposition 2). Then the game $\Gamma^{a}$ has a solution $\left(\mu^{0}, \nu^{*}\right)$ defined by (11), i.e., there exists a saddle point in mixed strategies in this game.

Taking into account (10), inequalities (11) can be written as

$$
\begin{gathered}
\int_{\mathrm{X} \times \mathrm{X}} \max _{r=1, \ldots, N+1} \varphi_{r}(x, z) \mu(d x) \nu^{*}(d z) \leqslant \int_{\mathrm{X} \times \mathrm{X}} \max _{r=1, \ldots, N+1} \varphi_{r}(x, z) \mu^{0}(d x) \nu^{*}(d z) \leqslant \\
\leqslant \int_{\mathrm{X} \times \mathrm{X}} \max _{r=1, \ldots, N+1} \varphi_{r}(x, z) \mu^{0}(d x) \nu(d z)
\end{gathered}
$$


for all $\nu(\cdot) \in\{\nu\}$ and $\mu(\cdot) \in\{\nu\}$. Using the measure $\nu_{i}\left(d z_{i}\right)=\mu_{i}^{0}\left(d x_{i}\right)(i \in \mathbb{N})$ (and hence $\left.\nu(d z)=\mu^{0}(d x)\right)$ in the expression

$$
\varphi\left(\mu^{0}, \nu\right)=\int_{\mathrm{X} \times \mathrm{X}} \max _{r=1, \ldots, N+1} \varphi_{r}(x, z) \mu^{0}(d x) \nu(d z),
$$

we obtain $\varphi\left(\mu^{0}, \mu^{0}\right)=0$ by virtue of $(11)$. Similarly, $\varphi\left(\nu^{*}, \nu^{*}\right)=0$, and then it follows from (11) that

$$
\varphi\left(\mu^{0}, \nu^{*}\right)=0
$$

The condition $\varphi\left(\mu^{0}, \nu^{*}\right)=0$ and the chain of inequalities (11) by transitivity give

$$
\varphi\left(\mu, \nu^{*}\right)=\int_{\mathrm{X} \times \mathrm{X}} \max _{r=1, \ldots, N+1} \varphi_{r}(x, z) \mu(d x) \nu^{*}(d z) \leqslant 0 \quad \forall \mu(\cdot) \in\{\nu\} .
$$

In accordance with Proposition 1, we have

$$
0 \geqslant \int_{\mathrm{X} \times \mathrm{X}} \max _{r=1, \ldots, N+1} \varphi_{r}(x, z) \mu(d x) \nu^{*}(d z) \geqslant \max _{r=1, \ldots, N+1} \int_{\mathrm{X} \times \mathrm{X}} \varphi_{r}(x, z) \mu(d x) \nu^{*}(d z) .
$$

Therefore, for all $r=1, \ldots, N+1$,

$$
\int_{\mathrm{X} \times \mathrm{X}} \varphi_{r}(x, z) \mu(d x) \nu^{*}(d z) \leqslant 0 \quad \forall \mu(\cdot) \in\{\nu\} .
$$

Consider the following two cases.

Case I $(r=1, \ldots, N)$. Here, by (2) and the normalization of $\nu(\cdot)$, for $r=1$ we have

$$
\begin{gathered}
0 \geqslant \int_{\mathrm{X} \times \mathrm{X}} \varphi_{1}(x, z) \mu(d x) \nu^{*}(d z)= \\
=\int_{\mathrm{X} \times \mathrm{X}} \max _{i \in \mathbb{N}}\left\{f_{i}\left[z_{1}, x_{2}, \ldots, x_{N}\right]-f_{i}[z]\right\} \mu(d x) \nu^{*}(d z) \geqslant \\
\geqslant \int_{\mathrm{X} \times \mathrm{X}} f_{i}\left[z_{1}, x_{2}, \ldots, x_{N}\right] \mu(d x) \nu^{*}(d z)-\int_{X} f_{i}[z] \nu^{*}(d z) \int_{X} \mu(d x)= \\
=f_{i}\left[\nu_{1}^{*}, \mu_{2}, \ldots, \mu_{N}\right]-f_{i}\left[\nu^{*}\right](i \in \mathbb{N}) .
\end{gathered}
$$

For $r=2, \ldots, N$ and $i \in \mathbb{N}$, the inequalities

$$
\begin{gathered}
0 \geqslant f_{i}\left[\mu_{1}, \nu_{2}^{*}, \mu_{3}, \ldots, \mu_{N}\right]-f_{i}\left[\nu^{*}\right], \\
\ldots \\
0 \geqslant f_{i}\left[\mu_{1}, \ldots, \mu_{N-1}, \nu_{N}^{*}\right]-f_{i}\left[\nu^{*}\right]
\end{gathered}
$$

are proved in the same way.

By Definition $2, \nu^{*}(\cdot)$ is a coalitionally rational profile in mixed strategies in the game $\Gamma^{g}$. 
Case II $(r=N+1)$. Again, using (2) and the normalization of $\nu(\cdot)$ and $\mu(\cdot)$,

$$
\begin{gathered}
0 \geqslant \int_{\mathrm{X} \times \mathrm{X}}\left[\sum_{i \in \mathbb{N}} f_{i}[x]-\sum_{i \in \mathbb{N}} f_{i}[z]\right] \mu(d x) \nu^{*}(d z)= \\
=\int_{\mathrm{X}} \sum_{i \in \mathbb{N}} f_{i}[x] \mu(d x) \int_{X} \nu^{*}(d z)-\int_{\mathrm{X}} \mu(d x) \int_{\mathrm{X}} \sum_{i \in \mathbb{N}} f_{i}[z] \nu^{*}(d z)=\sum_{i \in \mathbb{N}} f_{i}[\mu]-\sum_{i \in \mathbb{N}} f_{i}\left[\nu^{*}\right] .
\end{gathered}
$$

According to Remark 3, the mixed strategy profile $\nu^{*}(\cdot) \in\{\nu\}$ of the game $\Gamma^{g}$ is a Pareto maximal alternative in the $N$-criteria choice problem

$$
\widetilde{\Gamma}_{v}^{g}=\left\langle\{\nu\},\left\{f_{i}[\nu]\right\}_{i \in \mathbb{N}}\right\rangle .
$$

Thus, we have proved that the mixed strategy profile $\nu^{*}(\cdot)$ in the game $\widetilde{\Gamma}^{g}$ is a coalitionally rational profile in mixed strategies that satisfies Pareto maximality. Hence, by Definition 2 , the pair $\left(\nu^{*}, f\left[\nu^{*}\right]\right)$ is a coalitional equilibrium in mixed strategies in the game $\widetilde{\Gamma}^{g}$.

\section{Conclusion}

Let us summarize the new results on cooperative games obtained in this paper.

First, we have formalized the concept of coalitional equilibrium (CE) considering the interests of any coalition in a cooperative $N$-player game.

Second, we have developed a constructive method of CE design which is based on calculation of the minimax strategy for a special Germeier convolution associated with the guaranteed payoffs of the players.

Third, we have proved existence of CE in mixed strategies under standard assumptions of mathematical game theory (continuous payoff functions, compact strategy sets, and compact uncertainties).

In our view, an important role is also played by qualitative properties that directly follow from the analysis above.

1. The CE $x^{*} \in X$ is stable against the deviations of any admissible coalitions: by modifying their strategies, the players of a coalition either worsen their guaranteed payoffs or obtain the same guaranteed payoffs as before.

2. CE is applicable even if the coalitional structures evolve during the cooperative game (in particular, if all coalitions remain invariable).

3. CE can be used to construct stable unions (alliances) of players; as well as other advantages of CE!

As a matter of fact, there exists another merit worth mentioning.

The conditions of individual and collective rationality have always been in the focus of researchers who study cooperative games. But the individual interests of players well fit the concept of Nash equilibrium with its intrinsic selfish character ("to each his own"), while the collective interests of players match the concept of Berge equilibrium with its natural altruism ("help everybody, sometimes neglecting one's own interests"). However, such neglect is rather a phenomenon for the players as human beings. This negative feature of both concepts is eliminated by coalitional rationality.

Acknowledgements. The work was supported by Act 211 Government of the Russian Federation, contract no. 02.A03.21.0011. 


\section{References}

1. Zhukovskiy V.I., Kudryavtsev K.N. Equilibrating Conflicts Under Uncertainty. Analogue of a Maximin. Mathematical Game Theory and Its Applications, 2013, vol. 5, no. 2, pp. 3-45. (in Russian)

2. Zhukovskiy V.I. Kooperativnye igry pri neopredelennosti $i$ ikh prilozheniya [Cooperative Games under Uncertainty and Their Applications]. Moscow, Editorial URSS, 1999. (in Russian)

3. Nash J. Non-Cooperative Games. The Annals of Mathematics, 1951, vol. 54, no. 2, pp. 286-295. DOI: 10.2307/1969529

4. Nash J.F. Equillibrium Points in N-Person Games. Proceedings of the National Academy of Sciences, 1950, vol. 36, no. 1, pp. 48-49. DOI: 10.1073/pnas.36.1.48

5. Zhukovskiy V.I., Kudryavtsev K.N. Mathematical Foundations of the Golden Rule. Static Case. Automation and Remote Control, 2017, vol. 78, no. 10, pp. 1920-1940. DOI: $10.1134 /$ S0005117917100149

6. Bel'skikh Yu.A., Zhukovskiy V.I., Samsonov S.P. Altruistic (Berge) Equilibrium in the Model of Bertrand Duopoly. The Bulletin of Udmurt University. Mathematics. Mechanics. Computer Science, 2016, vol. 26, no. 1, pp. 27-45. DOI: 10.20537/vm160103 (in Russian)

7. Zhukovskiy V.I., Kudryavtsev K.N. Coalition Equilibrium in a Three-Person Game. Constructive Nonsmooth Analysis and Related Topics, 2017, vol. 1, pp. 1-4. DOI:10.1109/CNSA.2017.7974037

8. Kudryavtsev K.N., Zhukovskiy V.I. New Coalition Equilibrium under Uncertainty. CEUR Workshop Proceedings, 2017, vol. 1987, pp. 350-355.

9. Zhukovskiy V.I., Kudryavtsev K.N. Pareto-Optimal Nash Equilibrium: Sufficient Conditions and Existence in Mixed Strategies. Automation and Remote Control, 2016, vol. 77, no. 8, pp. 1500-1510. DOI: 10.1134/S0005117916080154

10. Germeier Yu.B. Vvedenie v teoriyu issledovaniya operatsii [Introduction to the Operations Research Theory]. Moscow, Nauka, 1971. (in Russian)

11. Borel E. Sur les systemes de formes lineaires a determinant symetrique gauche et la theorie generale du jeu. Comptes rendus de l'Academie des sciences, 1927, vol. 184, pp. 52-53. (in French)

12. Von Neumann J. Theory of Games and Economic Behavior. Princeton, Princeton University Press, 1944.

13. Morozov V.V., Sukharev A.G., Fedorov V.V. Issledovanie operatsii $v$ zadachakh $i$ uprazhneniyakh [Operations Research in Problems and Exercises]. Moscow, Vysshaya shkola, 1986. (in Russian)

14. Dmitruk A.V. Vypuklyi analiz. Elementarnyi vvodnyi kurs [Convex Analysis. An Elementary Introduction]. Moscow, MAKSPRESS, 2012. (in Russian)

15. Vasin A.A., Krasnoshchekov P.S., Morozov V.V. Issledovanie operatsii [Operations Research]. Moscow, Akademiya, 2008. (in Russian)

16. Glicksberg I.L. A Further Generalization of the Kakutani Fixed Point Theorem, with Application to Nash Equilibrium Points. Proceedings of the American Mathematical Society, 1952, vol. 3, no 1 , pp. $170-174$. DOI: $10.2307 / 2032478$

Received October 7, 2019 


\title{
КООПЕРАЦИЯ В КОНФЛИКТЕ $N$ ЛИЦ ПРИ НЕОПРЕДЕЛЕННОСТИ
}

\author{
В.И. Жуковский, К.Н. Кудрявцев ${ }^{2,3}$, С.А. Шунайлова ${ }^{2}$, \\ И.С. Стабулит ${ }^{2}$ \\ ${ }^{1}$ Московский государственный университет им. М.В. Ломоносова, г. Москва, \\ Российская Федерация \\ ${ }^{2}$ Южно-Уральский государственный университет, г. Челябинск, \\ Российская Федерация \\ ЗЧелябинский государственный университет, г. Челябинск, \\ Российская Федерация
}

В работе рассматривается модель конфликтной системы с $N$ активными участниками, имеющими собственные интересы, и при воздействии неопределенного фактора. При этом лица, принимающие решения, не имеют никакой статистической информации о возможной реализации неопределенного фактора, им известно лишь множество возможных реализаций этого фактора - неопределенностей. С учетом предположения о том, что в процессе принятия решения стороны конфликта могут согласовывать свои действия, модель формализуется как кооперативная игра $N$ лиц без побочных платежей и при неопределенности. В статье вводится новый для теории игр принцип коалиционной равновесности. Интеграция индивидуальной и коллективной рациональности (из теории кооперативных игр без побочных платежей) и этого принципа позволяет формализовать соответствующую концепцию коалиционного равновесия (CE) для модели конфликта $N$ лиц в условиях неопределенности. При этом учет неопределенности проводится с помощью концепции «аналога максимина», предложенного ранее в работах авторов, и построенных на его основе «сильных гарантий». Далее в работе устанавливаются достаточные условия существования коалиционного равновесия, которые сводятся к построению седловой точки для свертки Гермейера гарантированных выигрышей. Следуя подходу Э. Бореля, Дж. Фон Нейман и Дж. Нэша, доказывается существование коалиционного равновесия в классе смешанных стратегий при стандартных предположениях математической теории игр (компактность множества неопределенностей, компактность множества стратегий и непрерывность функций выигрыша). В конце статьи рассматриваются некоторые возможные направления для дальнейших исследований.

Ключевые слова: кооперативная игра; неопределенность; свертка Гермейера; игра гарантий.

\section{Литература}

1. Жуковский, В.И. Уравновешивание конфликтов при неопределенности. II. Аналог максимина / В.И. Жуковский, К.Н. Кудрявцев // Математическая теория игр и ее приложения. - 2013. - Т. 5, № 2. - С. 3-45.

2. Жуковский, В.И. Кооперативные игры при неопределенности и их приложения / В.И. Жуковский. - М.: Эдиториал УРСС, 1999.

3. Nash, J. Non-Cooperative Games / J. Nash // Annals of Mathematics. - 1951. - V. 54, № 2.P. 286-295.

4. Nash, J.F. Equillibrium Points in N-Person Games / J. Nash // Proceedings of the National Academy of Sciences. - 1950. - V. 36, № 1. - P. 48-49.

5. Zhukovskiy, V.I. Mathematical Foundations of the Golden Rule. I. Static Case / V.I. Zhukovskiy, K.N. Kudryavtsev // Automation and Remote Control. - 2017. - V. 78, № 10. - P. 1920-1940.

Вестник ЮУрГУ. Серия «Математическое моделирование

и программирование» (Вестник ЮУрГУ ММП). 2019. Т. 12, № 4. С. 29-40 
6. Бельских, Ю.А. Альтруистическое равновесие (по Бержу) в модели дуополии Бертрана / Ю.А. Бельских, В.И. Жуковский, С.П. Самсонов // Вестник Удмуртского университета. Математика. Механика. Компьютерные науки. - 2016. - Т. 26, № 1. - С. 27-45.

7. Zhukovskiy, V.I. Coalition Equilibrium in a Three-Person Game / V.I. Zhukovskiy, K.N. Kudryavtsev // Constructive Nonsmooth Analysis and Related Topics. - 2017. - V. 1. P. 1-4.

8. Kudryavtsev, K.N. New Coalition Equilibrium under Uncertainty / K.N. Kudryavtsev, V.I. Zhukovskiy // CEUR Workshop Proceedings. - 2017. - V. 1987. - P. 350-355.

9. Zhukovskiy, V.I. Pareto-Optimal Nash Equilibrium: Sufficient Conditions and Existence in Mixed Strategies / V.I. Zhukovskiy, K.N. Kudryavtsev // Automation and Remote Control. 2016. - V. 77, № 8. - P. 1500-1510.

10. Гермейер, Ю.Б. Введение в исследование операций / Ю.Б. Гермейер. - М.: Наука, 1971.

11. Borel, E. Sur les systemes de formes lineaires a determinant symetrique gauche et la theorie generale du jeu / E. Borel // Comptes rendus de l'Academie des sciences. - 1927. - V. 184. P. 52-53.

12. Von Neumann, J. Theory of Games and Economic Behavior / J. Von Neumann, O. Morgenstern. - Princeton: Princeton university press, 1944.

13. Морозов, В.В. Исследование операций в задачах и упражнениях / В.В. Морозов, А.Г. Сухарев, В.В. Федоров. - М.: Наука, 1986.

14. Дмитрук, А.В. Выпуклый анализ. Элементарный вводный курс / А.В. Дмитрук. - М.: MAKC Пресс, 2012.

15. Васин, А.А. Исследование операций / А.А. Васин, П.С. Краснощеков, В.В. Морозов. М.: Академия, 2008.

16. Glicksberg, I.L. A Further Generalization of the Kakutani Fixed Point Theorem, with Application to Nash Equilibrium Points / I.L. Glicksberg // Proceedings of the American Mathematical Society. - 1952. - V. 3, № 1. - P. 170-174.

Владислав Иосифович Жуковский, доктор физико-математических наук, профессор, кафедра «Оптимальное управление», Московский государственный университет им. М.В. Ломоносова (г. Москва, Российская Федерация), zhkvlad@yandex.ru.

Константин Николаевич Кудрявцев, кандидат физико-математических наук, доцент, кафедра «Математический анализ и методика преподавания математики», Южно-Уральский государственный университет (г. Челябинск, Российская Федерация); доцент, кафедра «Теория управления и оптимизация», Челябинский государственный университет (г. Челябинск, Российская Федерация), kudrkn@gmail.com.

Светлана Александровна Шунайлова, кандидат физико-математических наук, доцент, кафедра «Математический анализ и методика преподавания математики», Южно-Уральский государственный университет (г. Челябинск, Российская Федерация), shunailovasa@susu.ru.

Ирина Станиславовна Стабулит, старший преподаватель, кафедра «Вычислительная математика и высокопроизводительные вычисления», Южно-Уральский государственный университет (г. Челябинск, Российская Федерация), irisku76@mail.ru.

Поступила в редакиию 7 октября 2019 г. 